\title{
Social Ecology and Urban Green Spaces in Ibadan, Nigeria
}

\author{
*AREOLA, AA; IKPORUKPO, CO \\ Department of Geography, University of Ibadan, Nigeria \\ *Corresponding Author Email: biodunareola@yahoo.com Contact Number: (+234)8102022128
}

\begin{abstract}
This study analyses and explains the spatial pattern of urban green spaces based on a new approach, the application of the concept of social ecology with data collected from 3410 respondents selected across the 104 communities in Ibadan using stratified random sampling technique of projected population of Ibadan for 2015 estimated at 1,783, 367 with four sample percentages, $0.1 \% 0.2 \%, 0.4 \%$ and $0.8 \%$ respectively. Bivariate correlation analysis of SPSS version 21 was used to determine the significant social ecology indicators at $\mathrm{P} \leq 0.05$. Results show that the spatial pattern of green spaces was clustered indicating an uneven distribution of the benefits and burdens of urban green spaces for the year 2015. There are significant relationships between green spaces occurrence and such social ecology indicators as occupation $(\mathrm{P}=$ $0.001)$, income $(\mathrm{P}=0.002)$ and housing type $(\mathrm{P}=0.002)$. Thus, the distribution of green spaces is a function of the various social structures in existence in the metropolis. The commonly used indicators for social ecology in the literature for geographical studies are income, race and education. This study identified two additional possible indicators: occupation, and housing type.
\end{abstract}

\section{DOI: $\underline{\text { https://dx.doi.org/10.4314/jasem.v22i7.19 }}$}

Copyright: Copyright $(92018$ Areola and Ikporukpo. This is an open access article distributed under the Creative Commons Attribution License (CCL), which permits unrestricted use, distribution, and reproduction in any medium, provided the original work is properly cited.

Dates: Received: 31 May 2018; Revised: 30 July: 2018; Accepted: 21 July 2018

Keywords: social ecology, urbanization, green spaces, GIS

Rapid urbanization results in the conversion of several urban lands into built up structures and in excessive destruction of the natural ecosystem including green spaces (Honu et al., 2009; Barredo and Demicheli, 2003; Berry, 1990; Akerlund et al., 2006). Green spaces support sustainable urban development by recycling carbon, absorbing pollutants, providing clean air, soil and water, stabilizing urban temperatures and humidity, providing habitats for wildlife and maintaining or even improving biodiversity.

But, in addition, the social benefits of urban green spaces are also numerous. Scholars have pointed out that well-managed and maintained green spaces contribute to social inclusion and justice, provide cultural links and opportunities for community events, provide an educational resource with regard to the environment and nature, and help improve the physical, psychological and mental health of locals of all ages by providing areas for recreation and exercise. Thus, from a social perspective, urban green areas have a significant impact on a wide range of issues ranging from community involvement and empowerment, to matters of safety, inclusion, equality, civic pride, education and recreation (Loukaitou-Sideris, 2004; Nicol and Blake, 2000;
Ellaway et al., 2001; Takamo et al., 2002). The role of social ecology in explaining spatial pattern and processes in the environment cannot be overemphasized (Young, 1974; Bell et al., 2008; Maller et al., 2002; Tzoulas et al., 2007; Bookchin 2005; Brennan 1988; Bookchin 1992; Dai, 2011; Davoudi, 2012; Fanan, 2011). Social ecology focuses on the possibility that the foundations of ecological crises lie in social structures, or the multiple cause-and-effect relationships linking social ecological systems status and health (Young, 1974; Young et al., 2006; Folke et al., 2007; Dietz et al., 2007; Rosa, 2004). In terms of the variables to measure under social ecology concept, demographic characteristics other than population size have been identified to be permissible in the model most especially since the human ecosystem comprises of four interacting components: population, social organization, environment, and technology (Duncan, 1964; Bookchin, 1964; 2005; 2007; Anderson et al., 2007; Radin, 1960).

Biophysical factors such as biogeography and climate are also considered important contextual factors conditioning the social structural drivers of environmental impacts (Dietz et al., 2007). Furthermore, some authors investigated the workability of some variables under the social ecology 
concepts. First, they are of the opinion that population size is consistently the primary driver of environmental threats, except for CO2. Second, affluence is a major driver (the primary driver of $\mathrm{CO} 2$ emissions), though the magnitude of effect varies between different types of environmental impact and thirdly other contributing include population composition, urbanization, and climate (Dietz et al. 2007; Rosa 2004). Within a city, urban green spaces are mostly unevenly distributed over space and, are therefore disproportionately available to a subset of the urban population (Ernstson, 2013). Case study research in European and US cities has shown that different immigrant communities have less access to urban green spaces in their vicinity than the permanent residents. Comber et al., (2008) showed that Hindu and Sikh groups have limited access to urban green spaces in the city of Leicester. Dai (2011) found that in the city of Atlanta, mainly African-Americans have significantly lower access to urban green spaces in their neighborhoods. The main goal of this study therefore was to examine the relationship between the distribution of green spaces and social ecology in a city.

\section{MATERIAS AND METHODS}

Description of the study area: Ibadan is a major Nigerian city that was for a long time allowed to grow without a masterplan. Consequently, there is a great mix of activities such as residential and commercial, and sometimes residential and industrial as in the case of small to medium sized industrial establishments (Ayeni, 1994). Ibadan metropolis, covering an area of $129.65 \mathrm{~km}^{2}$, is located in south-western Nigeria, 128 $\mathrm{km}$ inland northeast of Lagos and $530 \mathrm{~km}$ southwest of Abuja, the federal capital. It lies between latitude $3^{0} 3^{\prime} \mathrm{N}$ and $4^{0} 10^{\prime} \mathrm{N}$ and longitude $7^{\circ} 2^{\prime} \mathrm{E}$ and $7^{0} 40^{\prime} \mathrm{E}$ (Figure 1). The population of Metropolitan Ibadan is 1 338, 659 according to census results for 2006.

Research Design and Sampling techniques: The study employed both a spatial and quantitative approach to gather the required data. The research design therefore involved mapping and measuring the green spaces of the study area as well as mapping the spatial distribution of the various social ecology indicators within the study area. A high resolution satellite image (SPOT) of Ibadan for the year 2015 was obtained from a remote sensing vendor to extract and measure the green spaces. Indicators on social ecology were collected through the administration of structured questionnaire (Table 1).

The questionnaire administration was carried out by field assistants who were graduate students of the University of Ibadan. The exercise took 32 weeks to complete. A questionnaire survey was carried out to investigate the spatial distribution of the various human groups based literature review. The community map of Ibadan metropolis (Figure 1) constituted the unit of measurement. A total of 104 communities were observed for Ibadan metropolis.

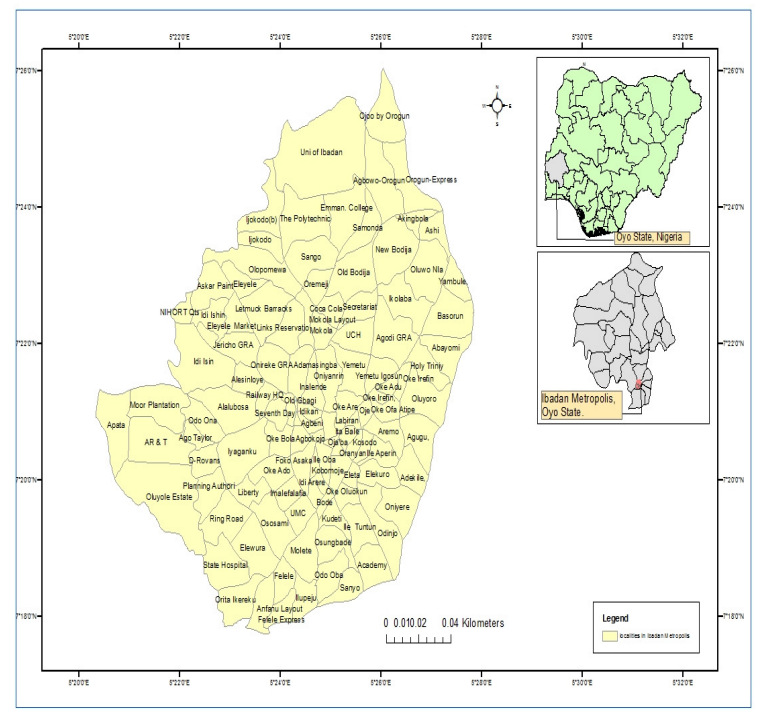

Fig 1: Ibadan Metropolis, Oyo State showing communities (Source: Ministry of Land and Survey, Oyo State)

The questionnaire were distributed by adopting the stratified random sampling technique in which Ibadan metropolis was divided based on the population density using four sample percentages $(0.1 \% 0.2,0.4 \%$ and $0.8 \%$ ). The total projected population for 2015 is estimated at 1,783,367 and the total questionnaire is estimated at 3,410 which will be distributed at regular an interval. The basis for the percentage is to have a fair representation of sample size across the communities. The social Ecology indicators comprises both the social characteristics of the people as well as the physical characteristics of the communities (Table 1).

Data Collection and Data Analysis: The social ecology indicators were collected through questionnaire administration to 3410 respondents based on the sampling technique. Geographic Information Systems (GIS) software (ARCGIS 10.4.1) was used for three purposes: (i) to extract and map the green spaces for the respective years; and (ii) to calculate the area of green spaces in square meter (sqm) at the community level for the year (2015). (iii) to determine the clustering pattern of green spaces for 2015 using Global Moran's I (pattern analysis). Bivariate correlation using SPSS version 21 was applied to determine the relationship between the occurrence of green spaces and the social indicators. 
Table 1: Social Ecology Indicators

\begin{tabular}{|c|c|}
\hline Indicators & Social Variables \\
\hline \multirow[t]{2}{*}{ Gender } & Male \\
\hline & Female \\
\hline \multirow[t]{6}{*}{ Age } & Less than 18 years \\
\hline & $18-28$ years \\
\hline & $29-38$ years \\
\hline & $39-48$ years \\
\hline & $49-58$ years \\
\hline & 59 and above \\
\hline \multirow[t]{3}{*}{ Ethnicity } & Yoruba \\
\hline & Ibo \\
\hline & Hausa \\
\hline \multirow[t]{3}{*}{ Religion } & Christianity \\
\hline & Islam \\
\hline & Tradition \\
\hline \multirow[t]{6}{*}{ Occupation } & Farming \\
\hline & Artisan \\
\hline & Civil/Public servant \\
\hline & Trading/Business \\
\hline & Student \\
\hline & Self employed \\
\hline \multirow{6}{*}{ Education } & No Formal \\
\hline & Education \\
\hline & Primary \\
\hline & Secondary \\
\hline & Tertiary \\
\hline & Quranic education \\
\hline \multirow[t]{6}{*}{ Income } & Less than 18,000 \\
\hline & $18-38,999$ \\
\hline & $39,000-58,999$ \\
\hline & $59-78,999$ \\
\hline & $79,000-98,999$ \\
\hline & 99,000 and above \\
\hline Indicators & Physical Variables \\
\hline \multirow[t]{8}{*}{ Housing Type } & Bungalow \\
\hline & Flat \\
\hline & Single Apartment \\
\hline & Story Building \\
\hline & Boys Quarter \\
\hline & Duplex \\
\hline & Hostel \\
\hline & Hut \\
\hline \multirow{5}{*}{$\begin{array}{l}\text { Housing Wall } \\
\text { Materials }\end{array}$} & Mud \\
\hline & Concrete \\
\hline & Wood \\
\hline & Bricks \\
\hline & Tiles \\
\hline \multirow{9}{*}{$\begin{array}{l}\text { Housing Roof } \\
\text { Material }\end{array}$} & Asbestos \\
\hline & Thatched \\
\hline & Pvc \\
\hline & Aluminum \\
\hline & Iron Roof Sheet \\
\hline & Concrete roof \\
\hline & Hey/Palm leaf \\
\hline & Metro Tiles \\
\hline & POP \\
\hline
\end{tabular}

\section{RESULT AND DISCUSSION}

Spatial Distribution of green spaces: In Ibadan metropolis, areas with large expanses of green spaces were to a large extent associated with government reserved areas (GRA), institutions of higher learning and research institutes/farms (Figure 2). The green space measurements carried out, show that majority of the communities now have small sized green spaces in the range $10,0000 \mathrm{~m}^{2}$ to $100,000 \mathrm{~m}^{2}$.

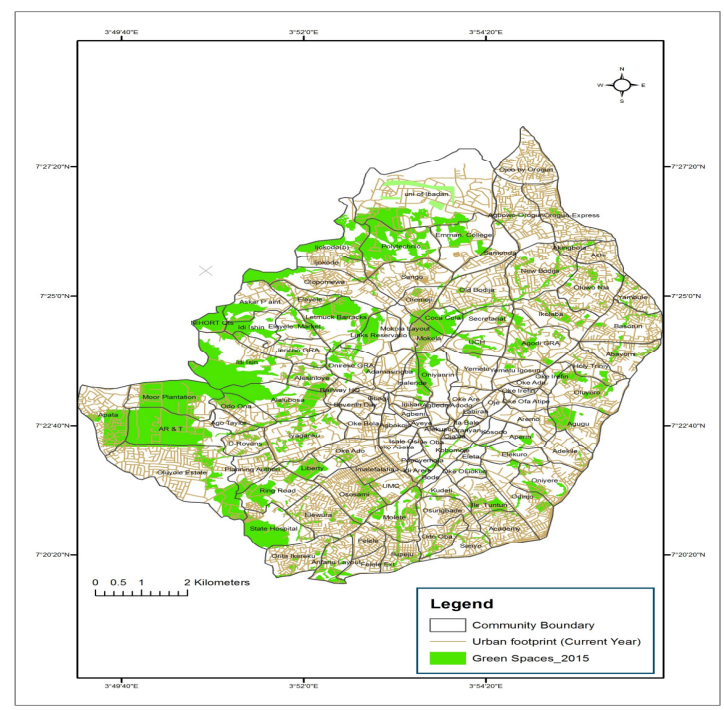

Fig 2: Distribution of Green Spaces in 2015

Source: Author GIS AnalysisIn addition to the explanations of the patterns of distribution of green spaces based on the map derived from remotely sensed image, a statistical test was carried out to characterize the spatial pattern of green spaces for 2015. The null hypothesis was that green spaces were randomly distributed in Ibadan Metropolis. Table 2 presents a summary of Global Moran's I analysis carried out for 2015. The results show a $P$ value of 0.000000 for a cluster pattern for 2015. This implies that given the Moran's Index value and the $\mathrm{z}$ - score for the respective years, there was a less than $1 \%$ likelihood that a clustered pattern could have occurred by a random chance (Fig 3). It can therefore be said that there was a positive significant spatial clustering of green spaces in Ibadan metropolis for the year 2015. In other words, communities with more green spaces are found together and communities where we have little or no green spaces are also found together.

Table 2: Summary of the Global Moran I's
\begin{tabular}{|l|l|}
\hline 2015 & \\
\hline Moran's Index: & 0.453937 \\
\hline Expected Index: & -0.007353 \\
\hline Variance: & 0.002307 \\
\hline z-score: & 9.603895 \\
\hline p-value: & 0.000000 \\
\hline
\end{tabular}




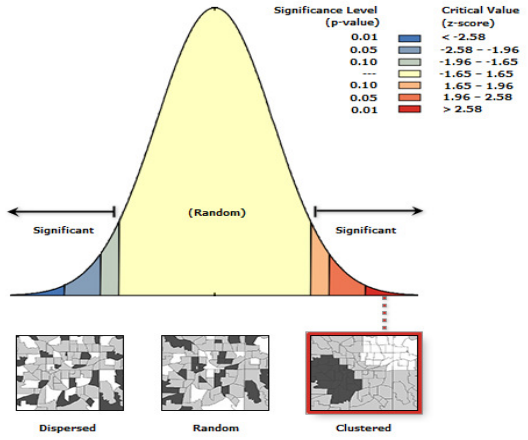

Fig 3: Clustering pattern for green spaces in Ibadan Metropolis (2015)

Spatial Distribution of the Social Ecology indicators: The social indicators covered the social characteristics of the people of Ibadan as well as the physical characteristics of their communities.

Social Characteristics of the people and the conceptual Implications:-One of the indicators of social ecology is gender. The goal here is to investigate if the spatial distributions of the male and female gender influence the spatial distribution of green spaces in the metropolis. The analysis of the questionnaire responses shows that in total the male gender $(54.9 \%)$ outweigh the female gender $(45.1 \%)$ in the metropolis and there is more concentration of the male gender in both high and medium residential areas suggesting middle income communities (Figure 4a). They primarily constitute the working class, more so the male than the female gender. It is mandatory for a man to provide for his family as compared to a woman. As such the man is hardly home to attend to domestic chores like keeping his environment clean and conducive. Such activities are left in the hands of the women folk. Also, a typical male will strive to maximize the exploitation of his surroundings and his profit hence the male folk invest in acquiring land for development and profit. The conceptual implication therefore is that green spaces will be concentrated more in areas that are dominated by the female gender as compared to the male gender. The concentration in the low income communities suggest that the male gender will rather spend more time in making ends meet than spending time in preserving green spaces.

Age as an indicator of social ecology will help to explain spatial variation of green spaces in relation to the spatial variation of able bodied people of the productive age class who are healthy enough to take care of their immediate environment. Results show that communities at the city centre that is those with low and medium income dominate at every age bracket, except the oldest group of 59years and above (Figure 4b).

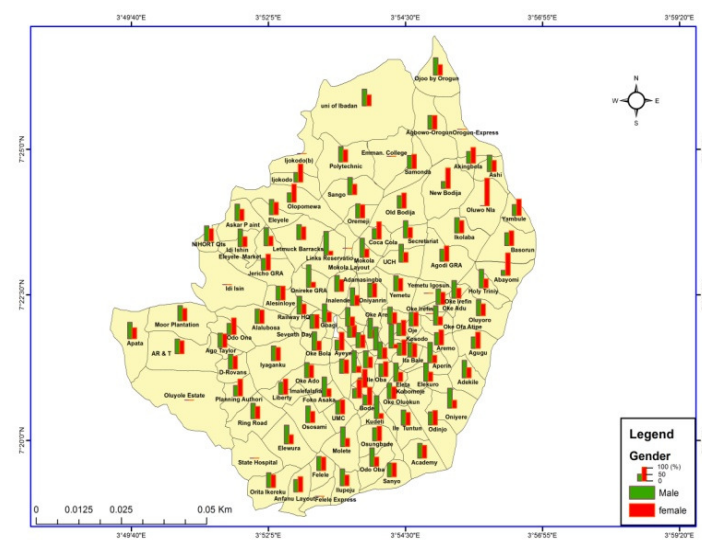

Fig 4a: Gender Group Source: Author Analysis, 2017

In addition, there are more elderly people 59 years and above in the traditional core areas of Ibadan. In total, the result are as follows; ( $<18$ years) $8.9 \%$; $(18-28$ years) $33.0 \%$; (29-38 years) 28.4 ; (39-48 years) 19.6 ; (49-58 years) 7.4 and lasty (59+) 2.7. Communities in the modern areas such as University of Ibadan, Bodija and the like, have more people in the middle and high age brackets (29-38 years and above), who should be able to take care of the environment and sustain in their surroundings. In general, the age distribution presents a fifty-fifty scenario (50-50).The conceptual implication is that of a fairly dispersed distribution of green spaces in the medium residential communities, and clusters of green spaces in the low density residential communities as compared to the high density residential communities with poor prospects of greening.

Ethnicity or race is one of the major indicators of social ecology. Internal migration is a common trend in Nigeria. The goal here is to examine the extent to which ethnicity could have influenced the spatial distribution of green spaces. The three major ethnic groups in Nigeria are Yoruba, Ibo and Hausa. How these ethnic groups are concentrated across the metropolis and what roles they play in the greening process are the focus of this analysis. Results show that middle- income communities had the highest proportions of all ethnic groups in the metropolis (Figure 4c). In total, the Yoruba group had the highest concentration of $70.8 \%$, followed by the Ibo group of $18.7 \%$. The Hausa group was the lowest at $10.5 \%$. The conceptual implication requires an understanding of the greening culture of each ethnic group, most especially their attitude towards the environment and their immediate surroundings. Findings from the field work conducted showed comparable levels of greening culture amongst the ethnic groups. 


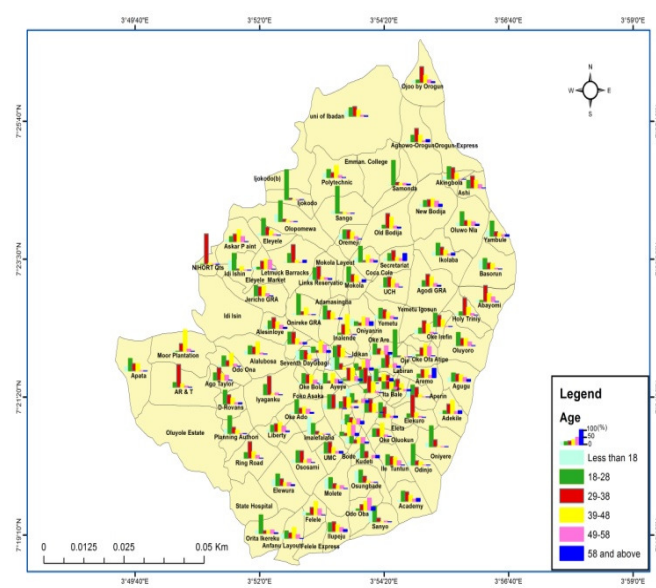

Fig 4b: Age Group Source: Author Analysis, 2017

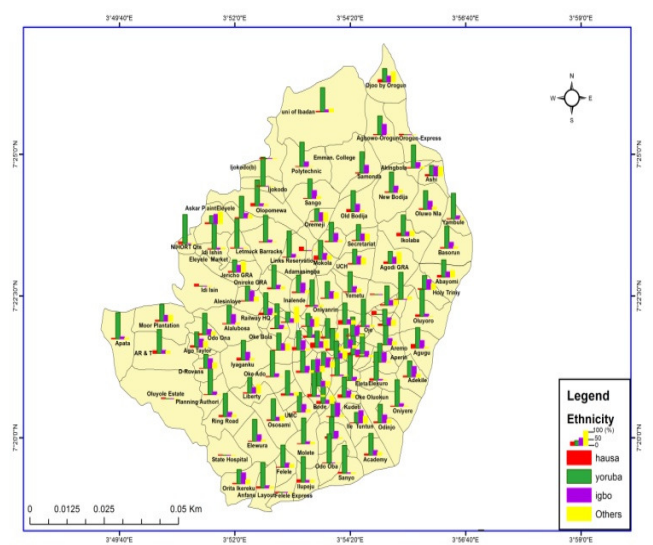

Fig 4c: Ethnicity Group Source: Author Analysis, 2017

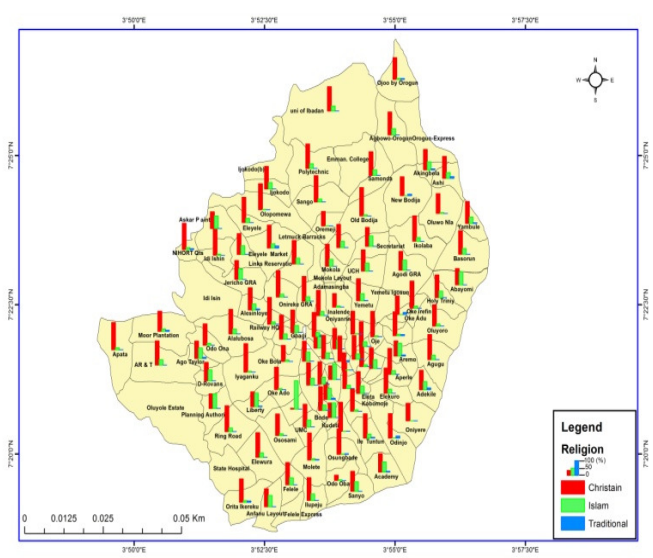

Fig 4d: Religion Group Source: Author Analysis, 2017 However, going by the educational status which will be explained better in subsequent paragraphs the Yoruba are the more educated among the sects and as such one would expect that their level of education would breed a positive attitude towards the environment. However, this might not be the case all the time. The Ibo and Hausa ethnic groups who are migrants in the city in pursuit of trade, industry and commerce may also be less concerned about greening issues. Therefore, ethnicity as an indicator cannot stand alone without a clear understanding of the behavioral patterns of the different ethnic nationalities. Religion is an indicator of social ecology. Few studies have investigated the extent to which religion affects the distribution of green spaces. In the Nigeria context, are the Muslims more conscious about maintaining the green spaces in their areas? Does traditional religion encourage respect for green spaces for example? Are the Christians more inclined toward greening or degreening? These are some of the issues that need to be addressed. Results of the questionnaire survey show that high concentration of Muslims is found in low and middle income communities especially the traditional core areas of the city (Figure 4d). In total, Christians constitute of $74.8 \%$ of respondents followed by the Muslims at $24.3 \%$ and lastly the traditional religion at about $0.9 \%$. The knowledge that plants are among the major materials used by the traditionalists, it could be expected that they would have higher respect for green spaces and green vegetation as compared to adherent of other religions. Going by the concept of social ecology it is expected that areas where there are concentrations of traditionalists would have considerable expanses of green spaces. However, in reality this might not be the case. There could be other constraining factors such as the level of commitment of these traditional worshipers, and their basic priority which is to make ends meet, etc.

Occupation is a major indicator of social ecology. The goal here is to relate the spatial distribution of green spaces to the spatial distribution of people in various occupational classes. Do communities dominated by civil/public servants have more green spaces than communities dominated by other occupational groups? In other words, is the spatial pattern of green spaces a function of the occupations of community residents? For instance, farmers spend more time in planting and harvesting while students spend more time in reading and going for classes. The results of the questionnaire survey show that the students are more concentrated in the high and mid- income communities such as Bodija, Agbowo (Figure 4e). The artisans, trading/business people and the civil/public servants are moderately evenly distributed across the the city. Farmers are widely dispersed but with discernible concentration in the outer parts of the city. In total, self-employed accounted for $1.7 \%$; farming 6.4\%; students 13.7\%; Artisian 19.2\%; civil/public servants $28.4 \%$; and trading/business $30.6 \%$. The conceptual implication is that areas dominated by students will have a relatively low occurrence of green spaces compared with communities dominated by the other occupation types. Students tend to pay less attention to their immediate environment in terms of 
maintaining a greening culture. They will rather prefer to engage in activities that give them pleasure or advance their knowledge. In addition studentdominated environments are usually characterized by commercial activities such as mini markets, barber shop, bar etc, which have little regard for greenery. Remarkably, the proportion of the self-employed is high in both the low and medium density communities (Figure 4e). One would also expect a relatively high expanse of green spaces in these areas dominated by such occupational types. The reason being that individuals determine their work schedule and are more in control of their time peradventure they have a greening culture. Having a greening culture means they will have time to maintain the green spaces in their immediate surroundings. This is usually common in estates (low residential density). Finally, it is important to draw attention to the fact that the high density residential areas contain high proportions of people in all the different occupations whereas the range of occupations represented in the low density communities is narrower.

The highest level of education as an indicator of social ecology is used to explain the possible role of education in the spatial distribution of green spaces. The literature has shown that the level of education can affect the attitude of people towards the environment. To the knowledgeable, green spaces in particular mean more than just the greening of the environment. In the long run, green spaces affect the climate of a region. The point being made is that spatial variations in the highest level of education (and probably in level of knowledge about environmental issues) might inidcate areas likely to have greater respect for green spaces.

The results from the questionnaire survey show that the medium density communities (i.e middle income earners) had the highest concentration of those with secondary school certificate, primary school certificate, and tertiary level education while those with no formal education at the buttom of the chart are well represented in the middle and high income communities, perhaps serving as househelps and labourers (Figure 4f). In total, those with No formal education were about $4.6 \%$; those with primary school certificate as their highest level of education, $7.2 \%$; secondary education, 45.4\%; and tertiary level education, 42.8\%. About $0.1 \%$ had only Quranic education.

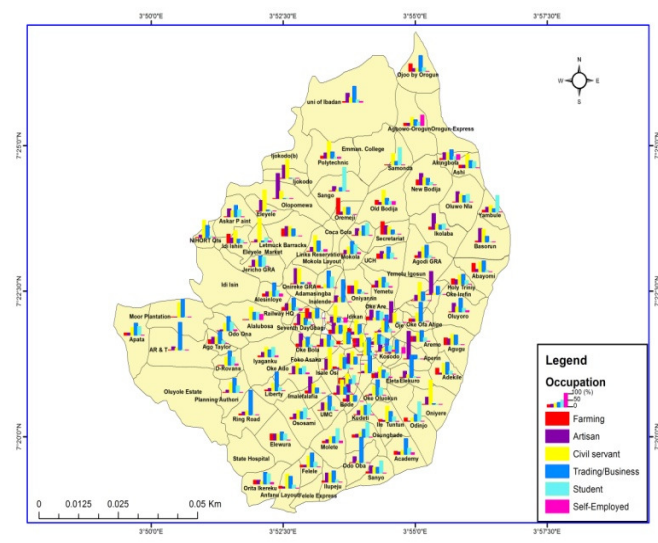

Fig 4e: Occupation Group Source: Author Analysis, 2017

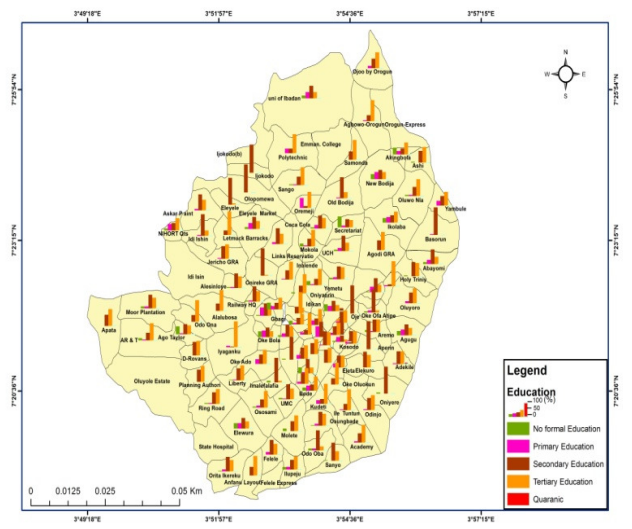

Fig 4f: Education Group ource: Author Analysis, 2017

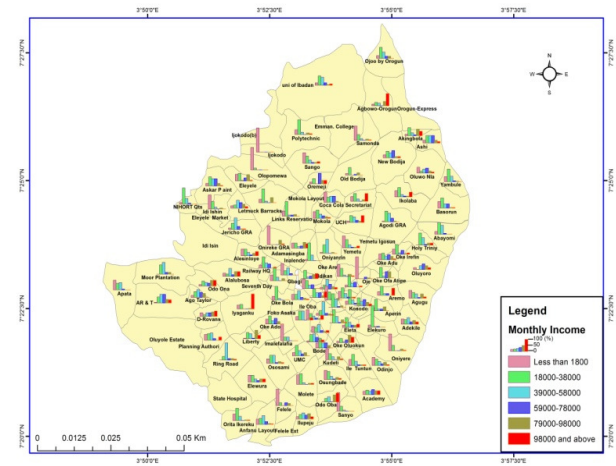

Fig 4g: Income Group Source: Author Analysis, 2017

The conceptual implication of this distribution is that the medium residential areas will have more spatial variation in greening as compared to the other residential zones. Furthermore, it would be expected that residents with tertiary level qualification would have more green spaces in their compounds as they should know the importance of green spaces and, hence, a greening culture. However, this might not be the case at all because there are other factors that affect a greening culture such as beliefs and personal hygiene. Moreover, those with high education might 
be too busy chasing their career with little or no time for preserving the green spaces in their environment. In general, education as a social ecology indicator, exhibits a dispersed spatial pattern across the metropolis.

Income is another major indicator of social ecology. Studies have shown that high income communities have the resources to maintain the green spaces around them. They are also conscious of their social stature (prestige) within their social circle hence they go the extra mile to beautify their immediate environment. They are mostly concentrated in the low density communities. This is unlike the low or middle class income earners whose priority is to survive and as such strive to cater for their basic needs (food and shelter). They do not have the luxury or the time for 'unprofitable' ventures. The results of the questionnaire survey show that those whose monthly income is above 99,000 naira reside in the medium and low density communities (Figure $4 \mathrm{~g}$ ). For the metropolis as a whole, the relative proportions are as follows: less than 18,000 naira (23.6\%); 18,000 $38,999(32.3 \%) ; 39,000-58,999(19.6 \%) ; 59,000$ $78,999(7.8 \%)$ and 79,000 $-98,999(9.2 \%)$ and lastly, 99,000 and above $(7.4 \%)$. The conceptual implication is that the medium density communities (working class) should have more green spaces as compared to the other residential density zones. This is because they have the resources to preserve the green spaces in their immediate environment and they also have their social status to protect compared to the other zones. However, this is not invariably the case as those in the medium density zone would rather spend their money on profitable ventures, and also majority of them are living in rented apartments. Those in the low density zone (e.g. estates) are likely to have more green spaces since they are land owners and they have the resources.

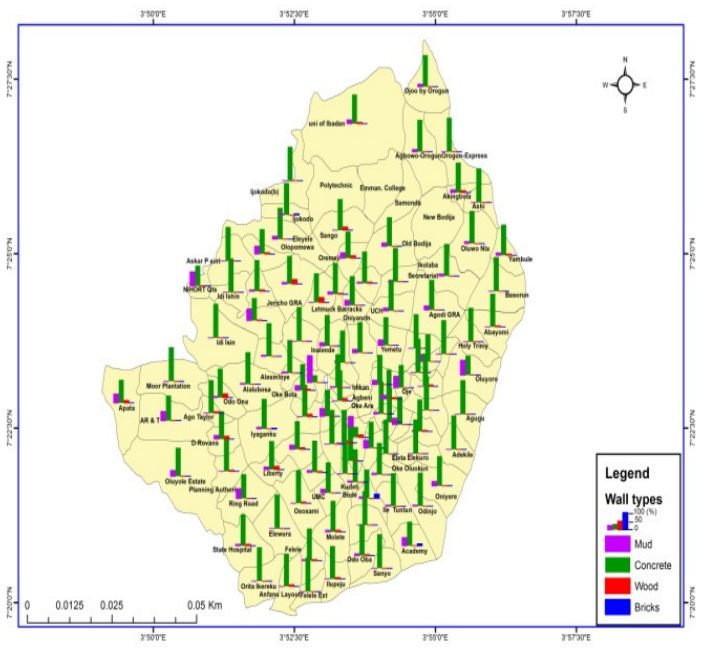

Fig 4h: Housing Type Source: Author Analysis, 2017

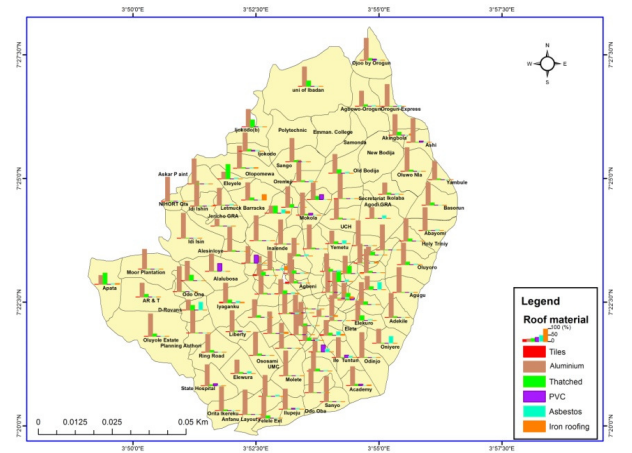

Fig 4i: Housing Wall Materials Source: Author Analysis, 2017

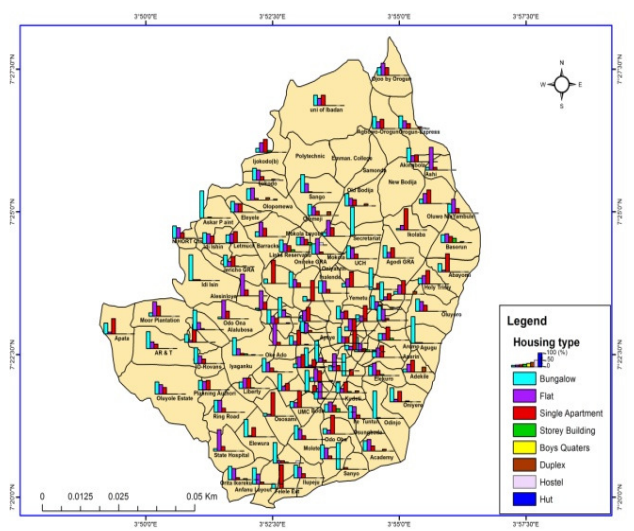

Fig 4j: Housing Roof Materials Source: Author Analysis, 2017

Physical Characteristics of the community and the conceptual Implications: The data analysis on housing types showed that communities in the medium density residential communities had the highest concentrations of bungalow, single apartment and flats respectively (Figure 4h). Hut, boys' quarters and hostel were the least frequent or common types of housing. In the metropolis as a whole, Bungalows dominate at $40.8 \%$, followed by flats, $28.7 \%$; single apartment, 28.1\%; Duplex, $1.1 \%$; storey building (0.8), Hostel 0.4\%; Boys' Quarters, $0.1 \%$. Hut housing type recorded $0.0 \%$. The conceptual implication is that green spaces would be concentrated more in communities with predominantly bungalow type housing since bungalows are associated with owner occupiers, hence the motivation to care for the immediate surroundings in contrast to those living in rented apartments. Housing wall materials in Ibadan metropolis include mud, concrete, bricks, cement blocks, wood and tiles. Concrete walls predominate in all communities. There is virtually no other type of wall material in the low density communities while the medium and high density communities accommodate small proportions of mud and wood walls (Figure $4 \mathrm{~h}$ ). Bricks and tiles are the least common across communities. In total, concrete material made up $89.7 \%$ of total; mud, $8.1 \%$; while wood, bricks, blocks and tiles recorded $1.7 \%, 0.2 \%, 0.1 \%$ and $0.1 \%$ 
respectively. The conceptual implication is that housing wall materials that are expensive could be associated with high income earners and according to the theory of planned behavior they will be in the best position to afford the cost of greening their immediate environment.

Several roofing materials are in use in Ibadan metropolis but asbestos roofing sheets far outstrip all others even in the high density communities (slum areas) (Figure 4i). Indeed, asbestos (78.6\%), zinc $(8.9 \%)$ and thatch $(6.7 \%)$ are the leading roofing materials across communities. The prominence of thatch relative to more modern materials is surprising, and it just shows that people are slow to change old habits. Other roofing materials found in the metropolis are aluminum material (2,4\%), PVC (about 1.5\%), iron roofing sheets $(0.7 \%)$, while concrete $(0.7 \%)$, POP $(0.7 \%)$, metro tile $(0.3 \%)$ and hay/palm $(0.3 \%)$. In terms of the conceptual implication affordability of the expensive roofing materials suggests possible positive attitudes towards green spaces in Ibadan metropolis. Maintenance of green spaces is expensive; therefore, one would expect green spaces to be more in areas where the most expensive roofing materials are used.

Bivariate Relationships between Social Ecology Indicators and Spatial Distribution of Green Spaces: Available literature have shown that the social ecology of a geographical space can influence positively or negatively the pattern of occurrence of an object of interest. One of the goals of this study is to determine if a relationship exists between the social ecology of Ibadan communities and the spatial distribution of green spaces. In other words, do the social ecology indicators (Socio-economic characteristics) influence the distributional pattern of green spaces in the metropolis? Table 2 presents a summary of the results of the bivariate correlation analysis in which 55 independent variables were considered (see table 1). The results show that there is a significant relationship between green spaces and four variables, namely, (i) Occupation (Artisan), (ii) Housing Type (Hut), (iii) Housing Type (single apartment), and (iv) Income $(18,000-38,999)$.

Table 2: Bivariate Correlation *(Significant Variables)

\begin{tabular}{lccl}
\hline Variables & $\begin{array}{l}\text { Correlation } \\
(\mathbf{r})\end{array}$ & $\begin{array}{l}\text { P- } \\
\text { value }\end{array}$ & $\begin{array}{l}\text { Level of } \\
\text { Significance }\end{array}$ \\
\hline Green spaces and Artisan & $0.194^{*}$ & 0.048 & Significant \\
Green spaces and 18-38,999 & $0.200^{*}$ & 0.042 & Significant \\
Green Spaces and Single & $0.191^{*}$ & 0.002 & Significant \\
Apartment & & & \\
Green Spaces and Hut & $0.197^{*}$ & 0.045 & Significant \\
\hline
\end{tabular}

$+r$ indicates positive relationship (they both move in the same direction) Source: Author's Analysis 2017; - $r$ indicates negative; elationship (they both move in the opposite directions); $p$-value $(p<0.05)$ implies that the relationship is statistically significant; $p$-value $(p>0.05)$ implies that the relationship is not statistically significant

Occupation as an indicator shows that there is a significant relationship between occupation and the distributional pattern of green spaces with reference to the specific occupation type, artisan at a $\mathrm{P}$ value of 0.048 . The implication of this is that green spaces are more likely to be found more in communities where there are artisans. This could probably be due to the fact that artisans are usually found in particular sections of the metropolis and are attached to their workshops, and do not really interact that much with their immediate surroundings like other occupation types. Furthermore, even though they rely on wood from trees, most of their wood materials are usually bought outside their immediate environments (e,g, from sawmills or from suppliers). Furthermore, the statistical analysis shows a significant relationship between income level and green spaces with reference to a specific group; $18,000-39,999$ at a $\mathrm{P}$ value of 0.042 . The implication of this is that green spaces are likely to be found more in communities where incomes range between 18,000 and 39,000 naira as compared to the other income groups. The reason for this result could be that the income group between 18,000 and 39,000 naira comprises mainly of young graduates, dependants, students, and working class folks. These are likely to be driven more by their career pursuits or livelihood activities that will increase their income and help them meet their basic needs rather than spending time with nature or promoting greening activities. Lastly, housing type is one of the physical characteristics of each community and as an indicator of social ecology there is a significant relationship between housing types and the distributional pattern of green spaces with specific reference to housing type: "hut" at a $\mathrm{P}$ value of 0.045 and "single apartment" at a P value of 0.002 . The implication of this is that green spaces are more likely to be found in communities where housing types are huts or single apartments. Hut is associated with rural areas or areas that are of ancient origin and closer to nature. Such areas will have less human activities and are probably dominated by the aged who have respect 
for nature and do not have the vigor to engage in rigorous activities that will result in the drastic removal of green spaces. Single apartment on the other hand can be associated with the low income earners whose priority will be to strive to make ends meet especially the basic needs. A greening culture will therefore be weak as compared to those who are high income earners. In addition, living in single apartments suggests that one is a tenant and not a home owner. Therefore, the motivation to maintain the green spaces will be low as compared to owner-occupiers who might want to beautify their environment in order to sustain their prestige.

Conclusion: This study is a new contribution to studies on greening since previous studies did not consider using the known concept of social ecology to explain the processes behind the greening of a city at the community level. It was discovered that variations in social structures across the metropolis influenced significantly the distributional pattern of green spaces. Therefore the concept will help those in the research; planning and policy circles understand better the processes that account for the spatial and temporal variations of green spaces in a city.

Acknowledgment: Appreciation goes to all the people who participated in this research especially in the data collection process. Abiodun Ayooluwa Areola conceived and designed the methods, selected materials, assembled and analyzed the data and prepared the article. C.O. Ikporukpo provided extensive advice on the conceptual framework, arrangement and structure of the article as well as its content.

\section{REFERENCES}

Akerlund, U; Knuth, L., Randrup, TB; Schipperijn, J (2006). Urban and peri-urban forestry and greening in west and Central Asia: Experiences, constraints and prospects. FAO Livelihood Support Programme (LSP) Working Paper 36. Access to Natural Resources Sub-Programme, $111 \mathrm{pp}$.

Anderson, E; Barthel, S; Ahrné, K (2007). Measuring social-ecological dynamics behind the generation of ecosystem services, Ecological Applications, Vol.17 No.5, pp. 1267-1278.

Barredo, JI; Demicheli, L (2003). Urban sustainability in developing countries megacities: modeling and predicting future urban growth in Lagos. Cities; 20(5): 297-310.
Bell, S; Val H; Alicia M; Rothnie H; Travlou P; and Alves S (2008). Greenspace and Quality of Life: A Critical Literature Review. Stirling, UK: Greenspace Scotland paper; 2 -23.

Berry, BJ (1990). Urbanization. In B.L. Turner II, W. C. Clark, R. W. Kates, J. F. Richards, J. T. Mathews, and

W. B. Meyer (Eds.), The Earth As Transformed by Human Action: Global and Regional Changes in the Biosphere over the Past 300 Years, pp. 103119. Cambridge University Press, Cambridge.

Bookchin, M (1964). Ecology and Revolutionary Thought, initially published ecoanarchist journal New Directions in Libertarian Thought.pp 1 -33.

Bookchin, M (1992). Urbanization without cities: The rise and decline of citizenship. Montreal: Black Rose.

Bookchin.M (2005). The Ecology of Freedom: The Emergence and Dissolution of Hierarchy (San Francisco: Cheshire Books, 1982; revised edition Montreal: Black Rose Books, 1991; reprinted with a new introduction by AK Press, 2005. Pp 1 -17 .

Bookchin M (2007). What is Social Ecology? From Social Ecology and Communalism, AK Press, first printing, 2007.pp 1- 12.Brennan, A (1988). Thinking About Nature, An Investigation of Nature, Value and Ecology, Routledge, London.

Dai, D (2011). Racial/ethnic and socioeconomic disparities in urban green space accessibility: Where to intervene? Landscape and Urban Planning, 102(4),234-244.

Davoudi, S; Brooks, E (2012). Environmental Justice and the city. Global Urban Research Unit, School of Architecture, Planning and Landscape Newcastle University. Pp 10 -24.

Dietz, T; Eugene, A; Richard, Y (2007). Driving the Human Ecological Footprint. Frontiers of Human Ecology, 5(1): 13-18.ce, and Technology." Human Ecology Review, 1:277-300.

Fanan, U; Dlama, K; Oluseyi, I (2011). Urban expansion and vegetal cover loss in and around Nigeria's Federal capital city. Journal of Ecology and the Natural Environment, 3(1), 1-10. 
Folke, C (2007). Social-ecological systems and adaptive governance of the commons. Ecological Research 22:14-15. http://dx.doi.org/10.1007/s11284-006-0074-0.

Ellaway, A; Macintyrem, S; Kearns, A (2001). Perceptions of Place and Health in Socially Contrasting Neighbourhoods", Urban Studies, Vol. 38 No.12, pp. 2299-2316.

Ernstson, H (2013). The social production of ecosystem services: A frame-work for studying environmental justice and ecological complexity in urbanized landscapes. Landscape and Urban Planning, 109(1), 7-17.

Honu, YA; Chandy, S; Gibson, DJ (2009). Occurrence of non-native species deep in natural areas of the Shawnee Natural Forest, Southern Illinois, USA. Natural Areas Journal, 29(2): 177-187.

Loukaitou-Sideris, A (2004), Association between people, CABE space, 2004

Maller, C; Mardie, T; Brown, P; Leger, L (2002). Healthy Parks Healthy People: The Health Benefits of Contact with Nature in a Park Context: A Review of the Literature. Melbourne: Deakin University and Parks Victoria. No., (1), 23 -67.

Nicol, C; Blake, R (2000). Classification and use of open space in the context of increasing urban capacity, Planning practice and research, Vol. 15 No.3, pp. 193-210.

Radin, P (1960). The World of Primitive Man (New York: Grove Press), p. 211.

Rosa, EA. (2004). Tracking the Human Sources of Ecological Footprints: The STIRPAT Research Program. Presentation at Center for Environmental Policy, The Institute for International Studies, Stanford University, November 18, 2004.pp 1-34.

Takamo, T; Nakamura, K; Watanabe, M (2002). Urban residential environments and senior citizens' longevity in megacity areas: the importance of walkable greenspaces, Journal of Epidemiology and Community Health, Vol.56, pp. 913-918.

Tzoulas, K; Kalevi K; Venn, S; Yli-Pelkonen, V; Kaz;mierczak, A; Niemela, J; James P (2007). "Promoting Ecosystem Health and Human Health in Urban Areas Using Green Infrastructure: A Literature Review." Landscape and Urban Planning 81 (3): 167-178.

Young, GL (1974). "Human ecology as an interdisciplinary concept: A critical inquiry". Advances in Ecological Research. Advances in Ecological Research 8: 1-105. 